\title{
Mirídeos neotropicais, CCXXXI: Descrição do gênero Tucuruiella $n$. gen. (Hemiptera)
}

José C. M. Carvalho (')

\begin{abstract}
Resumo
Descrição de um novo gênero - Tucuruiella $\mathrm{n}$. gen. (Hemiptera, Miridae) e de três novas espécies: Tucuruiella amazonensis n. sp., Estirão do Equador, Amazonas; T. matogrossensis $n$. sp., Vera, Mato Grosso e T. tapajoensis n. sp., Sinop, Mato Grosso. Estão incluídas ilustrações dos hábitos do T. tapajoensis e genitália masculina das três novas espécies.
\end{abstract}

Estudando exemplares de Ortothylinae provenientes de várias localidades do Brasil, foram encontradas algumas espécies do complexo Ceratocapsus Reuter, tribo Ceratocapsini, que não se enquadram nesse gênero. Para abrigá-las genericamente, acha-se descrito neste trabalho o gênero acima, no qual se acham incluídas três espécies que não haviam sido ainda descritas.

Os desenhos que ilustram o texto são de autoria de Luiz Antônio Alves Costa e Paulo Roberto Nascimento, sob orientação do autor.

Tucuruiella $\mathrm{n}$. gen .

Orthotylinae, Ceratocapsini. Corpo alongado, ligeiramente mimético com formigas, pubescência composta de pêlos adpressos e pêlos longos, esparsos e erectos sobretudo nos ângulos anteriores do pronoto, fêmures e tíbias posteriores com cerdas ou espinhos muito longos (macho) ou pubescência normal (fêmeas), superfície do pronoto e dos hemiélitros levemente pontuadas.

Cabeça vertical, vértice plano, marginado posteriormente, olhos grandes, salientes, fortemente granulosos, contíguos ao pronoto, clípeo pouco saliente, jogo, loro, gena e búcula reduzidos; rostro alcançando as coxas medianas; antena com segmento I mais grosso que os demais, segmentos III e IV tão grossos quanto o II, fusiformes, pilosidade muito curta.
Pronoto estreitado para a frente, medianamente constrito atrás dos calos, disco convexo, margens laterais arredondadas, margem posterior reta; mesoscuto largamente descoberto, escutelo pequeno, pouco saliente.

Hemiélitros de lados paralelos (macho), ligeiramente conscritos no meio e alargados posteriormente (fêmea), embólio, fratura cuneal distinta, cúneo tão longo quanto largo na base; membrana biareolada, longa nos machos e relativamente curta nas fêmeas. Pernas de comprimento moderado, tarso e unhas do tipo Orthotylinae.

Espécie tipo do gênero: Tucuruiella tapajoensis $\mathrm{n}$. $\mathrm{sp}$.

Aproxima-se de Pamilia Uhler, 1887 do qual se diferencia pela ausência de sulco na margem basal do embólio pelo pronoto muito menos convexo. Possui também similaridade com Renodaeus Distant, 1893, porém não possui faixas prateadas escamiformes. De Ceratocapsus difere pelo aspecto mimético com formigas, pela pilosidade dos fêmures e tíbias nos machos e sobretudo pelo tipo de estrutura da genitália.

Tucuruiella amazonensis $\mathrm{n}$. sp. (Fig. 1 - 3)

Caracterizada pelo comprimento das cerdas das tíbias posteriores e pela estrutura da genitália do macho.

Macho: comprimento $3,4 \mathrm{~mm}$; largura 0,9 $\mathrm{mm}$. Cabeça: comprimento $0,2 \mathrm{~mm}$; largura $0,7 \mathrm{~mm}$; vértice $0,32 \mathrm{~mm}$. Antena: segmento I, comprimento $0,2 \mathrm{~mm}$; II, $1,0 \mathrm{~mm}$; III, $0,4 \mathrm{~mm}$; IV, $0,3 \mathrm{~mm}$. Pronoto: comprimento $0,6 \mathrm{~mm}$; largura na base $0,9 \mathrm{~mm}$. Cúneo: comprimento $0,44 \mathrm{~mm}$; largura na base $0,40 \mathrm{~mm}$ (holótipo).

(1) - Museu Nacional, Rio de Janeiro. 


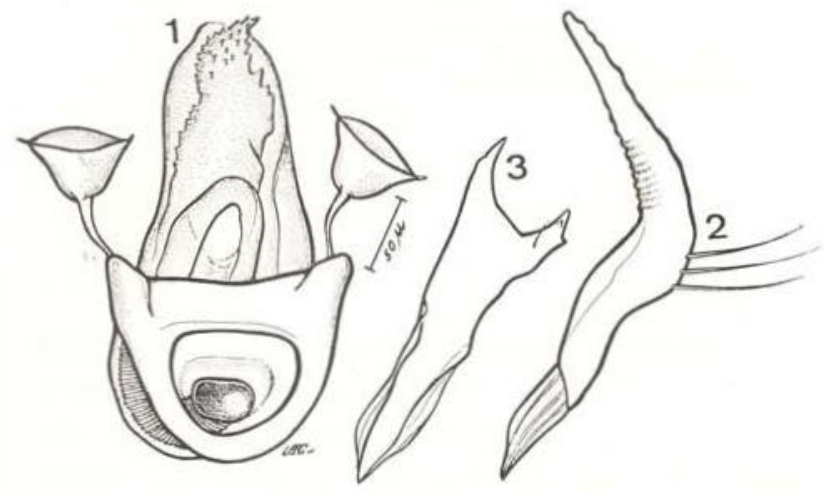

Tucuruiella amazonensis n. sp.: Fig. 1 - Penis; Fig. 2 - Parâmetro esquerdo; Fig. 3 - Parâmetro direito.

Coloração geral castanha; antena castanha, segmento I mais pálido, com uma mancha vermelha sub-basal internamente; disco do pronoto um pouco mais escuro; hemiélitro castanho escuro, mancha basal do cório e embólio, faixa transversal ao nível do ápice do clavo e membrana na base e área contígua ao cúneo pálidas. Lado inferior castanho, peritrema ostiolar, tíbias anteriores e medianas pálidos.

Corpo com pubescência adpressa e algumas cerdas erectas nos ângulos anteriores do pronoto; tíbias posteriores com cerdas extremamente longas.

Genitália: penis (fig. 1) com espículo mediano esclerosado tendo dentículos. Parâmero esquerdo (fig. 2) falciforme, com cerdas dorsais longas. Parâmero direito (fig. 3) bifurcado na extremidade apical, característico.

Fêmea: semelhante ao macho em aspecto geral, coloração mais clara. Dimensões aproximadamente iguais.

Holótipo: macho, Estirão do Equador. AM, BRASIL, X.79, Alvarenga col., na Coleção do Museu Nacional, Rio de Janeiro. Parátipo: fêmea, mesmas indicações que o tipo, na coleção do autor.

Difere das demais pelo comprimento das cerdas das tíbias posteriores e pela estrutura da genitália do macho

O nome respecífico é dado em alusão ao Estado do Amazonas onde está localizado o Estirão do Equador.
Tucuruiella matogrossensis $\mathrm{n} . \mathrm{sp}$.

(Fig. 4-6)

Caracterizado pela coloração do corpo e pela estrutura da genitália do macho.

Macho: comprimento $3,6 \mathrm{~mm}$; largura 1,2 $\mathrm{mm}$. Cabeça: comprimento $0,4 \mathrm{~mm}$; largura 0,8 $\mathrm{mm}$; vértice $0,30 \mathrm{~mm}$. Antena: segmento I, comprimento $0,4 \mathrm{~mm}$; II, $1,1 \mathrm{~mm}$; III, $0,8 \mathrm{~mm}$; IV, $0,5 \mathrm{~mm}$. Pronoto: comprimento $0,6 \mathrm{~mm}$; largura na base 1,1 mm. Cúneo: comprimento $0,3 \mathrm{~mm}$; largura na base $0,20 \mathrm{~mm}$ (holótipo).

Coloração geral castanha com áreas pálido-amareladas; cabeça (inclusive olhos e antenas), pronoto e escutelo castanhos; hemiélitros de cor variável: clavo castanho-escuro, fusco na porção basal; cório castanho com manchas basais (uma de cada lado) e faixa transversal apical pálidas; cúneo negro, membrana pálida na margem $€$ na porção basal intrareolar, porção mediana fusca. Lado inferior e pernas castanhos.

Pubescência composta de pêlos adpressos e cerdas erectas, carena do vértice com quilha bem evidenciada, olhos ocupando toda a parte lateral da cabeça, atingindo a gula inferiormente, rostro atingindo as coxas posteriores, tíbias (sobretudo as posteriores) com pêlos adpressos e cerdas erectas longas, de comprimento muito maior que a largura da tíbia, cúneo muito pouco mais longo que largo, antena do tipo Ceratocapsini, segmentos III e IV tão grossos quanto o II, fusiformes.

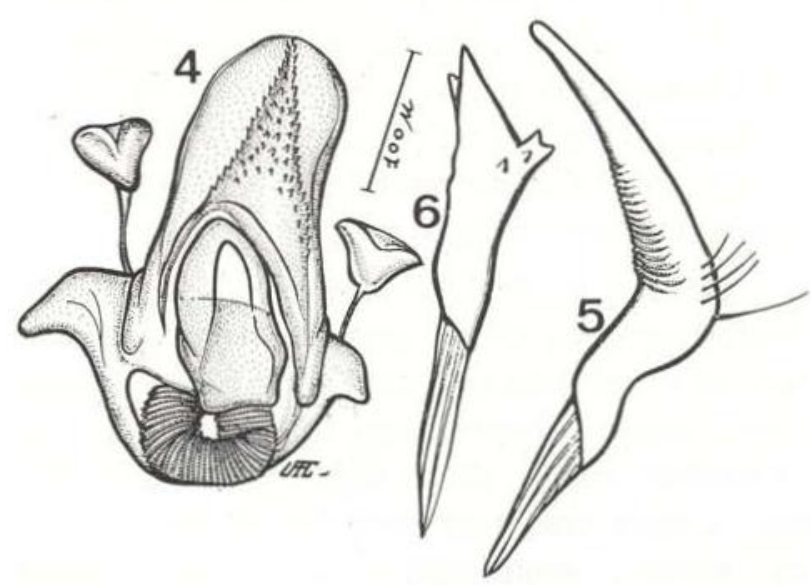

Tucuruiella matogrossensis n. sp.: Fig. $4-$ Penis; Fig. 5 - Parâmetro esquerdo; Fig. 6 - Parâmetro direito. 
Genitália: penis (fig. 4) com vésica provida de dentículos esclerosados. Pàrâmero esquerdo (fig. 5) falciforme, com ranhuras esclerosadas na porção mediana interna. Parâ. mero direito (fig. 6) característico, com dentículos apicais.

Fêmea: desconhecida.

Holótipo: macho, Vera, Mato Grosso, BRASIL, Alvarenga \& Roppa col., na coleção do Museu Nacional, Rio de Janeiro.

Espécie muito próxima de Tucuruiella tapajoensis $\mathrm{n}$. sp. na coloração geral e tamanho, diferenciando-se pela estrutura da genitália, sobretudo dos parâmeros esquerdo e direito.

O nome trivial é dado em alusão ao Estado de Mato Grosso, onde a espécie foi coligida.

Tucuruiella tapajoensis $\mathrm{n} . \mathrm{sp}$. (Fig. 7 - 12)

Caracterizada pela coloração geral e pela estrutura da genitália do macho.

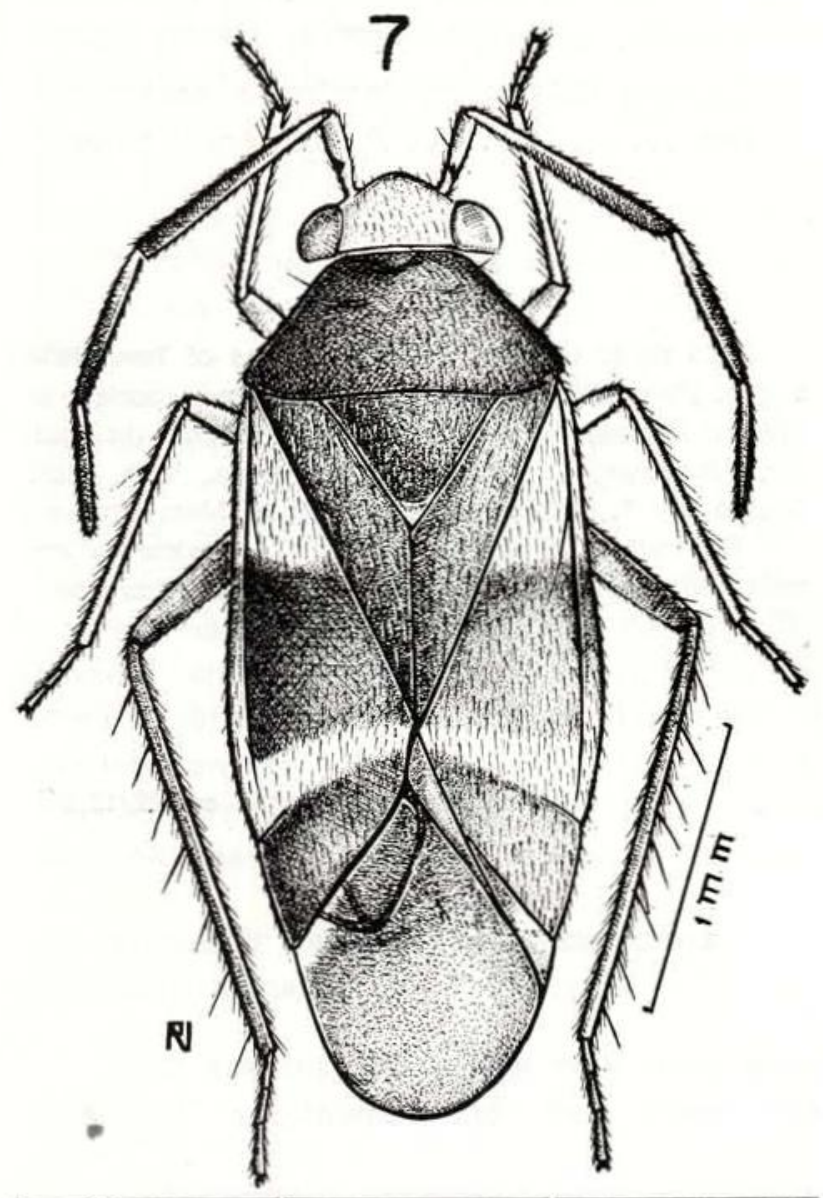

Fig. 7 - Tucuruiella tapajoensis n. sp., holótipo, macho.

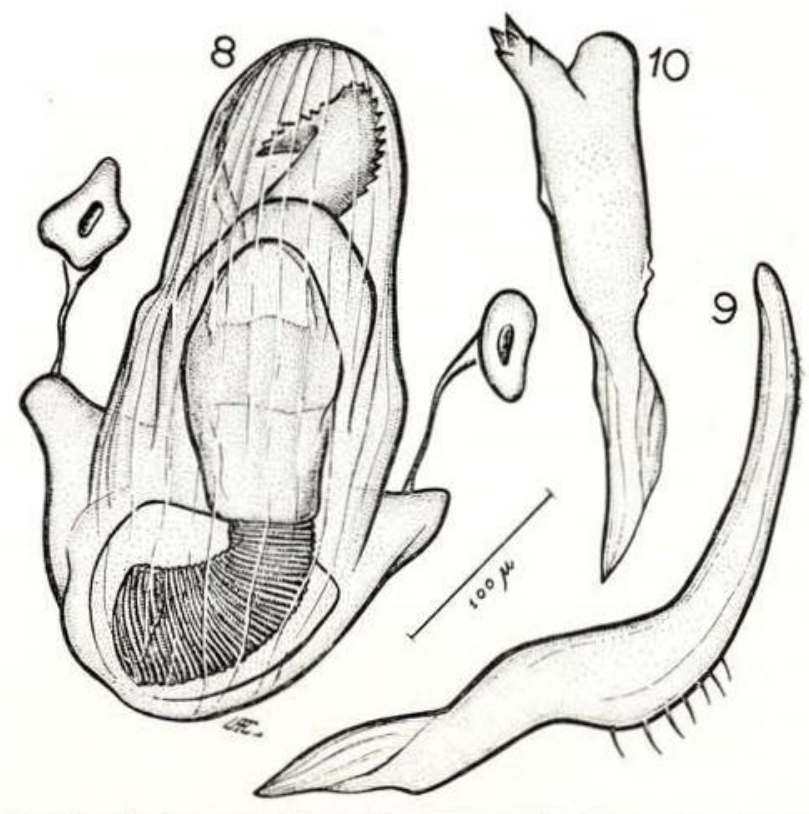

Tucuruiella tapajoensis n. $\overline{\text { sp.: Fig. } 8-\text { Penis; Fig. } 9}$ - Parâmetro esquerdo; Fig. 10 - Parâmetro direito.

Macho: comprimento $3,6 \mathrm{~mm}$; largura 1,1 $\mathrm{mm}$. Cabeça: comprimento $0.4 \mathrm{~mm}$; largura $0,8 \mathrm{~mm}$; vértice $0,30 \mathrm{~mm}$. Antena: segmento I, comprimento $0,4 \mathrm{~mm}$; II, $1,2 \mathrm{~mm}$; III, $0,7 \mathrm{~mm}$; IV, $0,5 \mathrm{~mm}$. Pronoto: comprimento $0,6 \mathrm{~mm}$; largura na base $1,0 \mathrm{~mm}$. Cúneo: comprimento $0,40 \mathrm{~mm}$; largura na base $0,20 \mathrm{~mm}$ (holótipo).

Coloração geral castanha, tendendo ao cinamómeo, com faixas claras; segmento I da antena pálido-amarelado (em alguns exemplares), com mancha vermelha sub-basal inferiormente; hemiélitros com faixa transversal apical no cório e duas manchas basais (uma de cada lado) no endocório pálidas; membrana fusca, área basal intrareolar e marginal pálidas. Lado inferior castanho, peritrema ostiolar e coxas pálido-amarelados; fêmures e tíbias castanhos.

Pubescência composta de pêlos adpressos e cerdas erectas, bem visiveis, no ângulo anterior do pronoto e margem interna do cúneo; pronoto e hemiélitros finamente pontuados; rostro atingindo as coxas posteriores.

Genitália: penis (fig. 8) com vésica tendo espículo esclerosado e revestido de dentículos esclerosados. Parâmero esquerdo (fig. 9) falciforme, alongado. Parâmero direito (fig. 10) característico, bifurcado no ápice, um dos lo. bos com dentículos. 

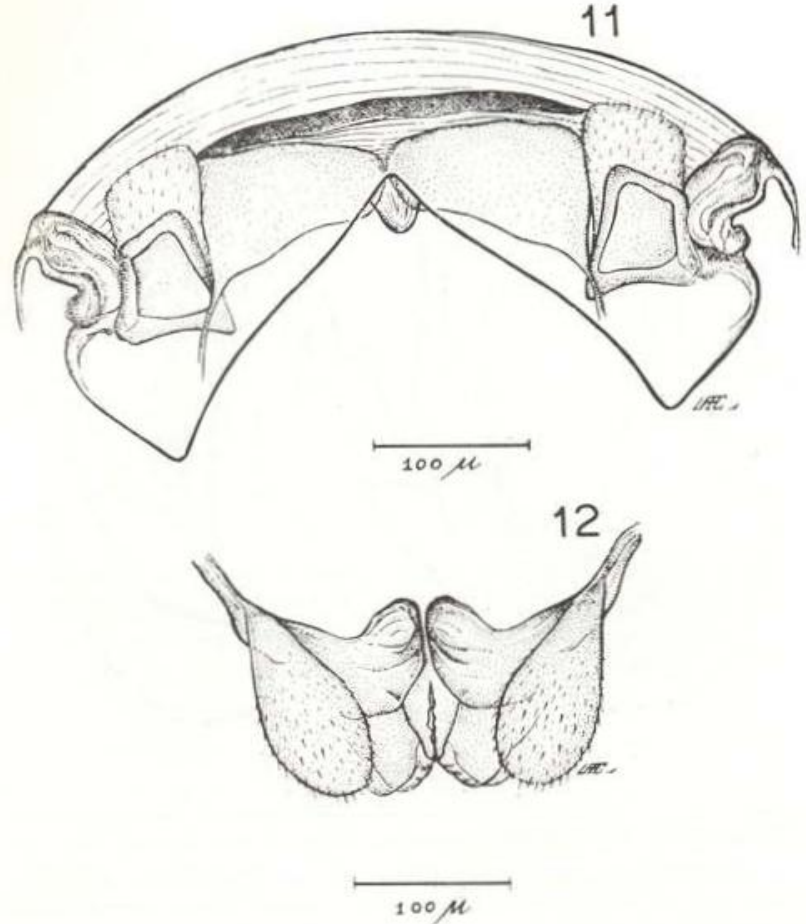

Tucuruiella tapajoensis n. sp.: Fig. 11 - Area dos anéis esclerosados; Fig. 12 - Parede posterior da câmara genital.

Fêmea: semelhante ao macho em aspecto geral, coloração e dimensões.

Genitália: área dos anéis esclerosados (fig. 11) e parede posterior da câmara genital (fig. 12) características para a espécie, conforme mostram as ilustrações.

Holótipo: macho, Sinop, $12^{\circ} 31^{\prime} \mathrm{S} 55^{\circ} 37^{\prime} \mathrm{W}$, $\mathrm{Br} 163, \mathrm{Km}$ 500-600, Mato Grosso, BRASIL, 360 m, X.1974, Alvarenga \& Roppa col., na coleção do Museu Nacional, Rio de Janeiro. Parátipos: 8 exemplares, mesmas indicações que o holótipo (4 fêmeas e 2 machos); Sinop. Rio Teles Pires, MT, Brasil, IX.74, Alvarenga \& Roppa (1 macho e 1 fêmea), na coleção do Autor.
Aproxima-se muito de Tucuruiella matogrossensis $\mathrm{n}$. $\mathrm{sp}$. da qual se diferencia pela estrutura da genitália do macho, notadamente dos parâmeros.

O nome trivial é dado em alusão ao rio Tapajós, nas vizinhanças do qual a espécie foi coligida.

\section{CHAVE PARA IDENTIFICAÇÃO DAS ESPÉCIES DE TUCURUIELLA $\mathrm{n}$. gen.}

1. Tíbias unicolores; parâmetro direito característico (fig. 6) Matogrossensis $\mathrm{n} . \mathrm{sp}$

- Tíbias anteriores e medianas pálidas na porção mediana; parâmetro direito de outra forma $\ldots \ldots \ldots \ldots \ldots \ldots \ldots \ldots \ldots \ldots$

2. Abdome tendendo ao vermelho ou avermelhado na margem superior; parâmetro direito com lobo apical arredondado (fig. 10) ........... Tapajoensis n. sp

- Abdome castanho; parâmetro direito bifurcado em duas pontas agudas (fig. 3), uma delas com dentículos esclerosados .............. Amazonensis $\mathrm{n}$. sp.

\section{SUMMARY}

This paper contains the descriptions of Tucuruiella n. gen. (Hemiptera, Miridae) and three new species, as follows: Tucuruiella amazonensis n. s., Estirão do Equador, Amazonas; T. matogrossensis n. sp., Vera, Mato Grosso and T. tapajoensis n. sp., Sinop, Mato Grosso.

Illustrations of the habitus of $\mathbf{T}$. tapajoensis and male genitalia of the three new species are included.

(Aceito para publicação em 22/12/81) 